\title{
The Bioavailability of Iron in Different Weaning Foods and the Enhancing Effect of a Fruit Drink Containing Ascorbic Acid
}

\author{
SUSAN FAIRWEATHER-TAIT, TOM FOX, S. GABRIELLE WHARF, AND JOHN EAGLES \\ Institute of Food Research, Norwich Laboratory, Norwich Research Park, Colney, Norwich NR4 7UA, \\ Norfolk, United Kingdom.
}

\section{ABSTRACT}

There is limited information on the bioavailability of Fe in infant weaning foods, mainly because of the difficulties of measuring Fe utilization directly in infants. The aim of this study was to develop a safe and relatively noninvasive method for studying $\mathrm{Fe}$ bioavailability (measured as percent $\mathrm{Fe}$ incorporation into red blood cells) in infants using ${ }^{54} \mathrm{Fe},{ }^{57} \mathrm{Fe}$, and ${ }^{58} \mathrm{Fe}$ stable isotopes. Four commonly used weaning foods were selected for study, labeled extrinsically with ${ }^{57} \mathrm{Fe}$ - or ${ }^{58} \mathrm{Fe}$-enriched ferrous sulfate, and fed to five female and five male 9-mo-old fasting infants, using a multiple-dosing technique. Each food was given three times, labeled with one isotope, with a fruit juice drink containing $50 \mathrm{mg}$ of ascorbic acid, and three times, labeled with a different isotope, with an ascorbic acid-free drink. Fourteen days after the last test meal, a blood sample was obtained from a heel-prick, spiked with a known amount of ${ }^{54} \mathrm{Fe}$, digested, and purified by ion exchange; isotopic enrichment and total Fe content were measured by quadrupole thermal ionization mass

A normal full-term infant is born with sufficient body $\mathrm{Fe}$ stores to satisfy physiologic requirements until at least 4 mo of age. By this time the stores will be depleted, and although $\mathrm{Fe}$ losses from the body are small, growth is very rapid; thus, the infant's needs for Fe must be met almost exclusively by the diet. In breast-fed infants, solid foods are the primary source of $\mathrm{Fe}$, because breast milk contains very little Fe. Formula-fed infants, however, have a higher total intake of Fe because the amount of $\mathrm{Fe}$ added to infant formulas is much higher than that found in breast milk to compensate for the lower bioavailability (1). Reports in the literature indicate that the intake of Fe-fortified formulas is one of the key determinants of Fe status of infants (2). However, if the Fe intake is not adequate, then nutritional $\mathrm{Fe}$ deficiency will begin to appear, usually after the age of 6 mo in a child with normal growth rate (3).

Reccived April 26, 1994; accepted November 15, 1994.

Correspondence and reprint requests: Dr. Susan J Fairweather-Tait, Institute of Food Research, Norwich Laboratory, Norwich Research Park, Colney, Norwich NR4 7UA, Norfolk, UK.

Supported by the Ministry of Agriculture Fisheries and Food spectrometry. The proportion of administered dose of isotope circulating in the blood was calculated from an estimate of blood volume. The geometric mean bioavailability (range) was 3.0\% $(1.2-9.5 \%)$ in a proprietary dehydrated vegetable product, $3.0 \%$ $(1.1-21.2 \%)$ in Weetabix whole-wheat breakfast cereal, 3.1\% $(1.2-15.4 \%)$ in wholemeal bread, and $4.3 \%(1.7-10.3 \%)$ in baked beans. When taken with the drink containing ascorbic acid, there was a 2-fold increase in bioavailability in all foods except the vegetable meal, presumably because this was already fortified with ascorbic acid. Thus, drinks containing $50 \mathrm{mg}$ of ascorbic acid, taken with a meal, can significantly improve $\mathrm{Fe}$ bioavailability to infants from weaning foods low in ascorbic acid. (Pediatr Res 37: 389-394, 1995)
ZPP, zinc protoporphyrin

\section{Abbreviations}
TIMS, thermal ionization mass spectrometry

Fe deficiency is still very common among infants and young children, both in industrialized and developing countries. Although inadequate intakes of $\mathrm{Fe}$ may result in $\mathrm{Fe}$ deficiency, the most likely cause is low bioavailability of ingested Fe. Dietary Fe is inefficiently absorbed by humans, and a number of dietary factors have been shown to inhibit or enhance the absorption of $\mathrm{Fe}$ (1). Present knowledge indicates that the most important dietary factors include ascorbic acid and meat (enhancers) and phenolics and phytate (inhibitors). From the limited number of studies already performed, the bioavailability of $\mathrm{Fe}$ in different weaning foods appears to be very variable (1). The demand for $\mathrm{Fe}$ in infants aged 6 mo or more is particularly high, yet little is known about the suitability of individual weaning foods and mixtures of foods with regard to Fe nutriture. One of the important questions this study was designed to answer was "what simple dietary advice can be given to mothers to improve their child's Fe nutrition?"

The most accurate technique for determining the bioavailability of $\mathrm{Fe}$ uses radioisotopes $\left({ }^{55} \mathrm{Fe}\right.$ and $\left.{ }^{59} \mathrm{Fe}\right)$ to label extrinsically the native food $\mathrm{Fe}(4)$, but, because of the hazards associated with unnecessary exposure to ionizing radiation, 
this method is not ethically acceptable in healthy infants. An alternative approach is to replace radioisotopes with stable isotopes of $\mathrm{Fe}(5)$. The present study was designed to measure Fe bioavailability using ${ }^{54} \mathrm{Fc},{ }^{57} \mathrm{Fe}$, and ${ }^{58} \mathrm{Fe}$ stable isotopes, in commonly used weaning foods, and to test whether or not a fruit juice drink containing ascorbic acid enhances Fe bioavailability from the foods.

\section{METHODS}

Subjects. Forty full-term apparently healthy infants (20 girls and 20 boys) aged 9 mo were recruited for the study and divided equally into four groups of 10 (five girls and five boys). None had been given Fe supplements immediately before the study. Blood was removed by heel-prick, and a portion of the whole heparinized blood was analyzed for hematologic indices using a CBC5 Coulter Counter (Coulter Electronics, Hialeah, FL) and ZPP using a hematofluorimeter (AVIV Associates, Bcdford, MA). The remaining blood was centrifuged, and the plasma was removed and stored at $-18^{\circ} \mathrm{C}$ until analysis for ferritin by ELISA. Subjects with Fe-deficiency anemia, $\mathrm{Hb}<$ $110 \mathrm{~g} / \mathrm{L}(6)$, were not accepted for the study. Mean values for body wcight, ZPP, and geometric means for plasma ferritin are given for boys and girls separately in Table 1, together with the numbers of infants in each group who were regularly consuming human milk, formula, or cow's milk during the period immediately before the study. Each group was given one of four sclected foods, labcled with a stable isotope of $\mathrm{Fe}$, with and without a drink containing ascorbic acid, and Fe bioavailability was asscssed from the measured isotopic enrichment of red blood cell $\mathrm{Hb} 14 \mathrm{~d}$ after the final dose.

Foods. Four of the most commonly used weaning foods that contribute significantly to $\mathrm{Fe}$ intake were selected for study, using information generated from a parallel study investigating the relationship between infant feeding practice and body $\mathrm{Fe}$ status, and fed to the different groups as follows: group 1, garden vegctables dinner (Milupa, Friedrichsdorf, Germany); group 2, Wcctabix brcakfast ccreal (Wectabix, Burton Latimer, Northants, UK) with full-fat milk; group 3, wholemeal bread (Allisons, Maidenhead, UK) with margarine and marmite [CPC (UK) Ltd., Esher, Surrey, UK]; and group 4, low sugar

Table 1. Body weight $(\mathrm{kg}), Z P P$ ( $\mu$ mol/L red blood cells), plasma ferritin $(\mu g / L)$, and type of milk consumed number of infants per group) in 9-mo-old boys and girls

\begin{tabular}{ccccccc}
\hline Group & Weight & ZPP & Ferritin & Human & Formula & Cows \\
\hline 1 Boys & $8.9(0.8)$ & $1.6(0.7)$ & $26(-11,+63)$ & 1 & 3 & 4 \\
Girls & $8.0(0.9)$ & $1.7(0.8)$ & $24(-15,+65)$ & 2 & 2 & 2 \\
2 Boys & $9.1(0.9)$ & $1.7(0.7)$ & $19(-9,+41)$ & 0 & 5 & 3 \\
Girls & $9.0(1.7)$ & $2.0(0.5)$ & $31(-22,+44)$ & 1 & 4 & 3 \\
3 Boys & $8.9(0.8)$ & $2.2(0.5)$ & $12(-6,+26)$ & 3 & 2 & 3 \\
Girls & $8.4(0.9)$ & $1.7(1.0)$ & $21(-11,+38)$ & 0 & 5 & 5 \\
4 & & & & & & \\
Boys & $9.1(0.6)$ & $2.1(0.9)$ & $22(-12,+39)$ & 2 & 2 & 4 \\
Girls & $8.6(1.2)$ & $1.4(0.5)$ & $20(-10,+35)$ & 1 & 3 & 4
\end{tabular}

Values are arithmetic means (geometric mean for ferritin) for five individuals $( \pm \mathrm{SD})$.
Table 2. Iron and ascorbic acid content of test meals fed to infants

\begin{tabular}{|c|c|c|c|c|}
\hline Food & Group & Wt $(g)$ & $\begin{array}{c}\mathrm{Fc} \\
(\mathrm{mg} / \mathrm{meal})\end{array}$ & $\begin{array}{l}\text { Ascorbic acid } \\
\text { (mg/mcal) }\end{array}$ \\
\hline Vegetable dinner & 1 & 25 & 0.95 & 63 \\
\hline Water & & 75 & & \\
\hline Wectabix & 2 & 20 & 0.72 & 3.8 \\
\hline Milk (full-fat) & & 85 & & \\
\hline Wholemeal bread & 3 & 22 & 0.59 & 0.3 \\
\hline Margarine & & 6 & & \\
\hline Marmite & & 0.5 & & \\
\hline Baked beans & 4 & 75 & 0.90 & 0.9 \\
\hline Apple juice drink & & 8 & 0.0 & 50 \\
\hline Water & & 92 & & \\
\hline
\end{tabular}

(Weight Watchers) canned baked beans in tomato sauce (H. J. Heinz Co. Ltd., Hayes, Middlesex, UK).

Two of the foods are normally fortified with Fe; Weetabix contains ferrous sulfate $(5.4 \mathrm{mg} \mathrm{Fe} / 100 \mathrm{~g}$ ) and Milupa meals contain ferric pyrophosphate ( $5 \mathrm{mg} \mathrm{Fe} / 100 \mathrm{~g}$ ). In this study, products without fortification $\mathrm{Fe}$ were specially prepared for us by the manufacturers, so that we were able to add isotopically enriched Fe in place of the fortification Fe. The Fe concentration was measured by atomic absorption spectrometry (7) and the ascorbic acid by HPLC (8), using 3\% metaphosphoric acid for the extraction. The portion sizes and $\mathrm{Fe}$ and ascorbic acid contents are given in Table 2.

Labeling of meals. Isotope solutions used for the study were prepared from ${ }^{57} \mathrm{Fe}$-enriched $(95.2$ atom $\%$, Technical and Optical Equipment, London, UK) and ${ }^{58} \mathrm{Fe}$-enriched $(93.13$ atom \%, AEA Technology, Harwcll, UK) elemental Fe. The Fe was dissolved by adding $5 \mathrm{~mL}$ of concentrated $\mathrm{HNO}_{3}$ (Aristar, BDH Poole, Dorset, UK) to each isotope $\left(103 \mathrm{mg}\right.$ of ${ }^{57} \mathrm{Fe}$ and $39 \mathrm{mg}$ of ${ }^{58} \mathrm{Fe}$ ) in silica crucibles, leaving it to stand overnight, warming it, and adding $5 \mathrm{~mL}$ of concentrated $\mathrm{H}_{2} \mathrm{SO}_{4}$ (Aristar, $\mathrm{BDH}$ Poole, Dorset, UK). The solutions were heated to drive off the $\mathrm{HNO}_{3}$, then taken to dryness and placed in a muffle furnace at $500^{\circ} \mathrm{C}$ for $30 \mathrm{~min}$. The resulting white powders were taken up in minimum volumes of $0.5 \mathrm{M} \mathrm{H}_{2} \mathrm{SO}_{4}$, and ascorbic acid was added $(0.83 \mathrm{mg}$ of ascorbic acid/mg of $\mathrm{Fe}$ ) to reduce all $\mathrm{Fe}$ to $\mathrm{Fe}^{2+}$. Natural abundance $\mathrm{Fe}$ as ferrous sulfate was added to the ${ }^{58} \mathrm{Fe}$ solution ( $1 \mathrm{mg}$ of $\mathrm{Fe}$ per $0.5 \mathrm{mg}$ of ${ }^{58} \mathrm{Fe}$ ). The ferrous sulfate solutions were dispensed in $5-\mathrm{mL}$ amounts, sealed in glass vials, autoclaved, and subjected to routinc sterility testing in the Pharmacy Department of the Norfolk and Norwich Hospital (St. Stephens, Norwich, UK). The final solutions contained $1.5 \mathrm{mg}$ of ${ }^{57} \mathrm{Fe} / 5 \mathrm{~mL}$ and $0.5 \mathrm{mg}$ of ${ }^{58} \mathrm{Fe}$ plus $1.0 \mathrm{mg}$ of natural abundance $\mathrm{Fe} / 5 \mathrm{~mL}$. The oxidation state of the $\mathrm{Fe}$ in ampoules stored for the longest timc $(12 \mathrm{mo})$ was checked using Ferrozine (Sigma Chemical Co., Poole, Dorset, $\mathrm{UK}$ ) and found to still be $100 \% \mathrm{Fe}^{2+}$.

Experimental protocol. A single portion of each weaning food, containing $0.55-0.95 \mathrm{mg}$ of native $\mathrm{Fe}$, was mixed with $1.5 \mathrm{mg}$ of $\mathrm{Fe}$ as fcrrous sulfate (enriched with ${ }^{57} \mathrm{Fe}$ or ${ }^{58} \mathrm{Fe}$ ) as an extrinsic label at least $1 \mathrm{~h}$ before consumption. Infants were fasted for at least $2 \mathrm{~h}$ before and after the test meals, with only 
water being allowed. Each meal was given with a commercial apple juice drink (Baby Ribena, SmithKline Beecham, Brentford, Middlesex, UK), containing $50 \mathrm{mg}$ of ascorbic acid per 8-g (undiluted) portion, or a placebo apple drink, containing no ascorbic acid. To ensure adequate isotopic enrichment of red blood cells and at the same time smooth out day-to-day variations in the efficiency of $\mathrm{Fe}$ absorption (9), a multiple-dose approach was adopted. Each infant received six labeled meals (three containing added ${ }^{57} \mathrm{Fe}$, given with one drink, and three with ${ }^{58} \mathrm{Fe}$, given with the other drink, different isotopes being given on alternate days) over a period not exceeding $10 \mathrm{~d}$. The total quantities of isotopes given to each infant were $4.5 \mathrm{mg}$ of ${ }^{57} \mathrm{Fe}$ and $1.5 \mathrm{mg}$ of ${ }^{58} \mathrm{Fe}$. The order of isotope administration was reversed in every other subject to eliminate any possible bias. All uneaten/spilt food was collected and analyzed by quadrupole TIMS (Finnigan-Mat, Bremen, Germany) to quantify enrichment with ${ }^{57} \mathrm{Fe}$ or ${ }^{58} \mathrm{Fe}$. This figure was deducted from the administered dose to calculate the quantity of isotope ingested by each infant. A blood sample was obtained from a heel-prick $14 \mathrm{~d}$ after the final test meal, and enrichment with ${ }^{57} \mathrm{Fe}$ and ${ }^{58} \mathrm{Fe}$ was measured.

Blood analysis. Blood $(\sim 250 \mu \mathrm{L})$ was collected into a heparinized polypropylene tube from a heel-prick $14 \mathrm{~d}$ after the last test meal. Subsamples of approximately $0.12 \mathrm{~g}$ were cleaned up for TIMS analysis. One milliliter of concentrated nitric acid (Aristar) was added to the subsample and left overnight in a loosely capped vial. To measure the total Fe content by isotope dilution mass spectrometry, an isotopic spike was added to the blood sample (approximately $0.16 \mathrm{~g}$, accurately weighed, of ${ }^{54} \mathrm{Fe}$ solution, $0.182 \mathrm{mg} \mathrm{Fe} / \mathrm{mL}, 96.59$ atom \%). The mixture was transferred to a Teflon-lined digestion vessel (CEM Microwave UK Ltd., Buckingham, $\mathrm{UK}$ ), and the vial was washed with $1 \mathrm{~mL}$ of concentrated $\mathrm{HNO}_{3}$ (Aristar) and $1 \mathrm{~mL}$ of quartz-distilled water. The digestion vessel was capped and heated in a microwave MDS 2000 oven (CEM Microware Ltd.) slowly to 90 pounds per square inch over $30 \mathrm{~min}$. The vessels were cooled, $1 \mathrm{~mL}$ of $\mathrm{H}_{2} \mathrm{O}_{2}$ (Aristar) was added, and the vessels were heated again to 90 pounds per square inch slowly over $60 \mathrm{~min}$. The digest was removed to polytetrafluoroethylene bcakers, the acid was evaporated in a laminar flow fume cupboard, and the digest was redissolved in $4 \mathrm{M} \mathrm{HCl}$ (Aristar).

Acid-washed glass columns, measuring $100 \mathrm{~mm}$ and $5 \mathrm{~mm}$ internal diameter, were packed with previously swelled BioRad AG 1-X8 resin (Bio-Rad Laboratories, Richmond, CA) and washed with $60 \mathrm{~mL}$ of $2 \mathrm{M} \mathrm{HNO}_{3}$ in an airtight system using a peristaltic pump. The resin was regenerated to the chloride form using $60 \mathrm{~mL}$ of $4 \mathrm{M} \mathrm{HCl}$, and the samples were loaded. After loading, the columns were washed with an additional $30 \mathrm{~mL}$ of $4 \mathrm{M} \mathrm{HCl}$, and the samples were eluted with $0.5 \mathrm{M} \mathrm{HCl}$, collected in a $1.5-\mathrm{mL}$ polyethylene microtube, and dried in a laminar flow cabinet under a $1-\mathrm{kW}$ lamp. The samples were redissolved in $0.2 \mathrm{M} \mathrm{HNO}_{3}$ and analyzed by TIMS (10). A standard and a solution of the ${ }^{54} \mathrm{Fe}$ spike were run for each batch of samples.

Calculation of Fe bioavailability. The isotopic ratios (R) $\left({ }^{54} \mathrm{Fe} /{ }^{56} \mathrm{Fe},{ }^{57} \mathrm{Fe} /{ }^{56} \mathrm{Fe},{ }^{58} \mathrm{Fe} /{ }^{56} \mathrm{Fe}\right)$ of samples, standards, and
${ }^{54} \mathrm{Fe}$ spike were measured, and from these the Fe concentration and ${ }^{57} \mathrm{Fe}$ and ${ }^{58} \mathrm{Fe}$ enrichment per $\mathrm{g}$ of blood was calculated using the following formula:

$$
R\left({ }^{54} /^{56}\right)=\frac{\frac{A_{n 54}}{W_{n}} n+\frac{A_{x 54}}{W_{x}^{-}} x+\frac{A_{y 54}}{W_{y}} y+\frac{A_{y 54}}{W_{z}} z}{\frac{A_{n 56}}{W_{n}} n+\frac{A_{x 56}}{W_{x}} x+\frac{A_{y 56}}{W_{y}} y+\frac{A_{z 56}}{W_{z}} z}
$$

where $\mathrm{A}=$ isotopic abundance, $\mathrm{W}=$ average molccular weight, $\mathrm{n}=$ weight of all isotopes of natural $\mathrm{Fc}, \mathrm{x}=$ weight of all isotopes of ${ }^{54} \mathrm{Fe}, y=$ weight of all isotopes of ${ }^{57} \mathrm{Fe}$, and $\mathrm{z}=$ weight of all isotopes of ${ }^{58} \mathrm{Fe}$. Similar equations were derived for $\mathrm{R}\left({ }^{57} /^{56}\right)$ and $\mathrm{R}\left({ }^{58} p^{56}\right)$. The values of $\mathrm{R}$ and $\mathrm{x}$ were known, so by combining the three simultaneous equations, values for $\mathrm{n}$, $y$, and $z$ could be calculated.

The total blood volume was estimated as $81 \mathrm{~mL} / \mathrm{kg}$ of body weight (11), and thus the total circulating Fe derived from the doses administered was calculated for each infant. This was expressed as a fraction of administered dose to give an estimate of bioavailability.

Statistical analysis. The percent incorporation of administered isotope into $\mathrm{Hb}$ (bioavailability) values were converted to logarithms for statistical analysis, and the results were reconverted to the antilogarithms to recover the original units (12). The incorporation of isotope into $\mathrm{Hb}$ (percent of administered dose) data were analyzed by two-way analysis of variance (13), using a computer program, with variables food type and ascorbic acid. Where a significant treatment effect was shown, differences in individual groups were examined using a onetailed $t$ test (14). The relationship between $\log _{10}$ plasma ferritin and $\mathrm{Fe}$ bioavailability $\left(\log _{10} \%\right.$ incorporation of $\mathrm{Fe}$ isotope into $\mathrm{Hb}$ ) from the meals was examined by regression analysis (14) using a computer program.

Ethical approval. Approval for this study was granted by the Institute of Food Research Human Research Ethics Committee, and every mother signed an informed consent form.

\section{RESULTS}

There were no differences in the weight, ZPP, or plasma ferritin between the four groups. Although $\mathrm{Hb}$ values were normal range, ZPP values were elevated, i.e. $>1.42$ suggested cut-off values (6), in $65 \%$ of the infants. The ferritin values were low, (see "Discussion") but only $17.5 \%$ had values $<12$ $\mu \mathrm{g} / \mathrm{L}$. This suggests that the cut-off value for ZPP is perhaps too low.

The mean percent $\mathrm{Hb}$ incorporation of isotope from the four meals is illustrated in Figure 1, given with and without a drink containing $50 \mathrm{mg}$ of ascorbic acid. In two subjects (one from the Weetabix group and one from the vegetable dinner group), the isotopic analysis gave poor duplicate results, and the size of blood sample obtained from these infants was insufficient to perform repeat analysis, thus these data were excluded from the results. The geometric mean percent incorporation of absorbed isotope into $\mathrm{Hb}$ from the foods given with the placebo drink ranged from 3.0 to $4.3 \%$. This increased to $4.0-8.6 \%$ when the foods were given with the apple juice drink contain- 


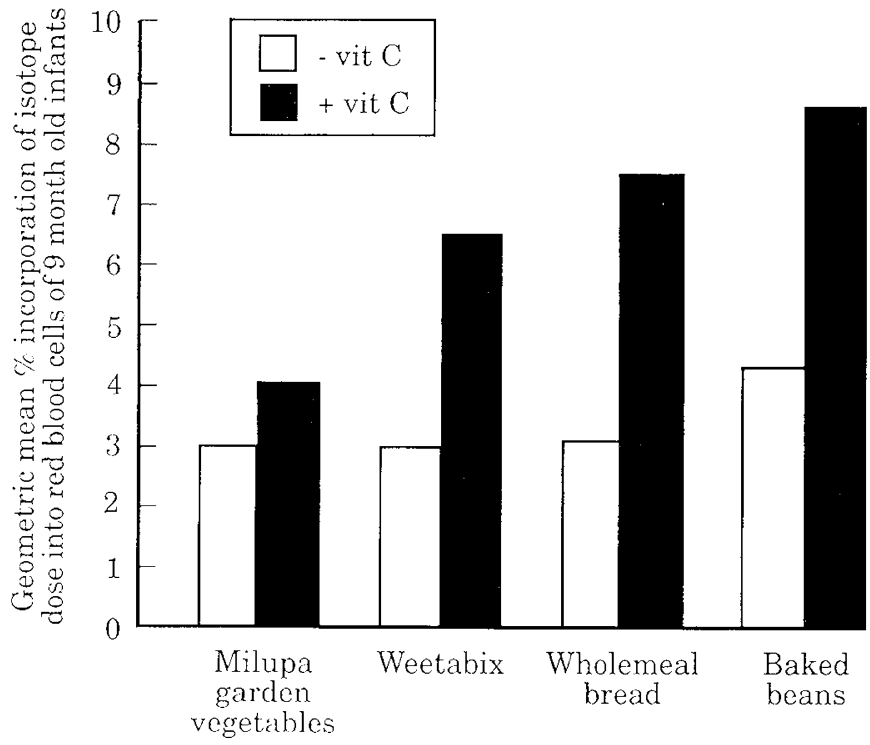

Figure 1. Fe bioavailability (percent incorporation of isotope dose into red blood cells) of sclected weaning foods, given to 9-mo-old infants, with and without a drink containing $50 \mathrm{mg}$ of ascorbic acid.

ing ascorbic acid. No difference was found between boys and girls.

The data were subjected to analysis of variance (Table 3), and it was shown that there were no significant differences in bioavailability between the foods, but that ascorbic acid significantly affected Fe uptake into red blood cells. When each food was examined scparately, it was found that ascorbic acid cnhanced $\mathrm{Fe}$ bioavailability from meals of Weetabix $(p<$ $0.05)$, wholemeal bread $(p<0.05)$, and baked beans $(p<$ 0.01 ), but not the garden vegetables dinner. The ascorbic acid content of each of the four meals is shown in Table 2, where it can be seen that the garden vegetables dinner contained $63 \mathrm{mg}$ of ascorbic acid (added by the manufacturers together with other micronutrients), whereas none of the other meals contributed a significant amount of ascorbic acid. The native $\mathrm{Fe}$ content of the test meals ranged from $0.59 \mathrm{mg}$ in the wholemeal bread to $0.95 \mathrm{mg}$ in the garden vegetables dinner.

The multiple dosing technique, together with ${ }^{54} \mathrm{Fe}$ spiking of samples, was sensitive enough to measure the total $\mathrm{Fe}$ content and detect $5 \%$ changes in isotopic enrichment of whole blood, and it required only very small volumes of blood (approximately $250 \mu \mathrm{L}$ ). Capillary blood can be obtained from a heelor finger-prick which requires a lower level of training than is needed for venipuncture, and in our experience, some mothers find hecl-pricks more acceptable than venipuncture.

\section{DISCUSSION}

The determination of Fe absorption by chemical balance is not reliable and does not provide information about individual foods or meals. The preferred methods of measuring Fe absorption and bioavailability use radioisotopes, but because of the potential hazards associated with ionizing radiation, studies of infant nutrition using radioisotopes have often been carried out in adults, thus there is limited knowledge about how well infants use Fe from different foods (15). There are, in fact, only
Table 3. Effect of type of food and ascorbic acid on percent incorporation of $\mathrm{Fe}$ into $\mathrm{Hb}$ in 9-mo-old infants

\begin{tabular}{|c|c|c|c|}
\hline Food & - Ascorbic acid & + Ascorbic acid & Significance \\
\hline \multirow[t]{10}{*}{ Vegetable dinner } & 1.2 & 2.7 & \\
\hline & 4.1 & 1.5 & \\
\hline & 1.6 & 3.2 & \\
\hline & 1.4 & 0.9 & \\
\hline & 2.5 & 3.4 & \\
\hline & 4.7 & 13.8 & \\
\hline & 3.2 & 5.0 & \\
\hline & 9.5 & 10.3 & \\
\hline & 4.2 & 8.4 & \\
\hline & Mean $3.0(1.5,5.9)$ & $4.0(1.6,9.7)$ & NS \\
\hline \multirow[t]{10}{*}{ Weetabix } & 1.1 & 3.3 & \\
\hline & 1.6 & 13.4 & \\
\hline & 3.7 & 4.6 & \\
\hline & 2.1 & 2.9 & \\
\hline & 1.1 & 2.4 & \\
\hline & 1.6 & 3.1 & \\
\hline & 7.5 & 10.3 & \\
\hline & 21.2 & 24.7 & \\
\hline & 5.7 & 19.1 & \\
\hline & Mean $3.0(1.1,8.3)$ & $6.5(2.7,16.0)$ & $p<0.05$ \\
\hline \multirow[t]{11}{*}{ Wholemeal bread } & 15.4 & 8.0 & \\
\hline & 1.6 & 3.1 & \\
\hline & 2.0 & 11.2 & \\
\hline & 5.5 & 9.5 & \\
\hline & 1.2 & 4.4 & \\
\hline & 3.9 & 9.3 & \\
\hline & 3.8 & 11.6 & \\
\hline & 1.3 & 8.9 & \\
\hline & 3.8 & 6.8 & \\
\hline & 3.4 & 7.7 & \\
\hline & Mean $3.1(1.4,6.7)$ & $7.5(5.0,11.4)$ & $p<0.05$ \\
\hline \multirow[t]{11}{*}{ Baked beans } & 3.6 & 6.4 & \\
\hline & 10.3 & 11.1 & \\
\hline & 1.9 & 9.9 & \\
\hline & 3.3 & 2.0 & \\
\hline & 5.7 & 13.0 & \\
\hline & 1.7 & 5.8 & \\
\hline & 4.4 & 10.4 & \\
\hline & 8.0 & 9.3 & \\
\hline & 3.1 & 23.7 & \\
\hline & 7.9 & 8.6 & \\
\hline & Mean $4.3(2.3,7.8)$ & $8.6(4.5,16.2)$ & $p<0.01$ \\
\hline
\end{tabular}

Individual and gcometric mean $(-\mathrm{SD},+\mathrm{SD})$ values.

a few isotopic studies in which Fe absorption from foods has been determined in infants, either by whole body counting (16), fecal balance (17), or $\mathrm{Hb}$ incorporation techniques (18). In recent years, efforts have been made to develop the methodology required to use stable instead of radioisotopes, so as to enable studies to be performed directly on infants by fecal monitoring (19) or red blood cell enrichment $(10,20-22)$. The present report presents results of a unique study in which two stable isotopes have been administered orally to infants, and a third one was used to quantify blood enrichment with the isotopes (bioavailability) from a small volume of capillary blood using isotope dilution mass spectrometry.

There was a large interindividual variation in percent $\mathrm{Fe}$ incorporation into $\mathrm{Hb}$ in the infants. In adults this is generally attributed to differences in Fe stores (measured by serum/ plasma ferritin concentrations). Fomon et al. (20) found a weak but significant relationship $(r=-0.337, p<0.03)$ between 
erythrocyte incorporation of ${ }^{58} \mathrm{Fe}$ added to infant foods and serum ferritin in 22-wk-old infants. A better correlation was reported in a smaller study involving nine infants aged $18 \mathrm{wk}$ (geometric mean $46.2 \mu \mathrm{g} / \mathrm{L}$, + SD 97.7, - SD 21.4) (Spearman $r=-0.867, p<0.01$ ) (21). However, in the present study, when the relationship between $\mathrm{Hb}$ incorporation (all foods fed without ascorbic acid) and plasma ferritin levels was examined (23), there was no significant correlation (Spearman $r=$ -0.212). Infants had lower body Fe levels and a smaller range in plasma ferritin concentrations (geometric mean $21.2 \mu \mathrm{g} / \mathrm{L}$, $+\mathrm{SD} 39.9,-\mathrm{SD} 11.3$ ). None of the infants in the smaller study was Fe deficient, whereas $17.5 \%$ of our 9-mo-old infants had depleted stores (plasma ferritin $<12 \mu \mathrm{g} / \mathrm{L}$ ). Using rats as an experimental model for man, we have shown that there is indeed a significant correlation between percent Fe absorption and $\mathrm{Hb}$ concentration (24) but that, when Fe-deficient and normal animals are examined as two separate groups, the correlation disappears. These results suggest that there is a threshold response whereby the efficiency of Fe absorption increases only when body stores are depleted. Most infants 6 mo of age or older are Fe-depleted, therefore perhaps the same phenomenon is occurring in the infants in the present study as was observed in rats. Our findings confirm those of Kastenmayer et al. (10), in which no significant correlation between serum ferritin concentration and percent Fe absorption in 13- to 25 -wk-old infants was found. Further work is required to determine at what age the well-established inverse relationship in adults between body Fe stores and efficiency of Fe absorption develops.

The chemical form of Fe that is added to weaning foods depends on a variety of factors, including organoleptic properties (taste, color), shelf-life and stability (oxidation of lipids), bioavailability, and cost. Often the most highly absorbable sources of $\mathrm{Fe}$ are unacceptably reactive in the food product, resulting in undesirable characteristics. The commercial whole-wheat breakfast cereal (Weetabix) is fortified with ferrous sulfate, but the dried garden vegetables dinner (Milupa) contains added ferric pyrophosphate. Because it was not possible to prepare stable isotopically labeled pyrophosphate, the well-absorbed salt ferrous sulfate was used for all of the test meals. In the case of Weetabix, the results obtained are a true measure of Fe bioavailability from the product as consumed by infants, but with the other foods the results are a measure of the effect of the food on $\mathrm{Fe}$ utilization from well-absorbed Fe. Absorption of ${ }^{59} \mathrm{Fe}$-labeled ferric pyrophosphate added to infant cereal was reported to be $39 \%$ of the ferrous sulfate values in adults (25), thus it is likely that Fe utilization from commercial Milupa meals would be lower than found in this study.

Fomon et al. (20) measured ${ }^{58} \mathrm{Fe}$ uptake into erythrocytes from labeled infant foods (rice cereal, vegetables and beef, and grape juice) in 22-wk-old infants. Mean values (percent of label incorporated into erythrocytes) ranged from $2.5 \%$ (vegetables and beef) to $5.4 \%$ (rice cereal with apples and bananas) These results are very similar to the results obtained in the present study for the foods given with the placebo drink. They found no significant differences between the foods, nor did the presence or absence of infant formula affect Fe bioavailability. However, because of practical considerations, the test meals contained differing quantities of Fe (1.1-4.6 mg). Because the efficiency of $\mathrm{Fe}$ absorption is known to be dose-related, direct comparison between meals of different Fe content can be misleading. In the present study we attempted to ensure that the total (native plus added isotope) Fe content of each test meal was similar (Weetabix, $2.2 \mathrm{mg}$; baked beans; $2.4 \mathrm{mg}$; bread, $2.1 \mathrm{mg}$; and garden vegetables dinner, $2.5 \mathrm{mg}$ ), but because $\mathrm{Fc}$ was added as a label, the Fe concentration of the foods was higher than that found commercially, even in the products to which no fortification $\mathrm{Fe}$ had been added. The Fe content $(\mathrm{mg} / 100 \mathrm{~g})$ in test meals and commercial products, respectively, was Weetabix, 11.1 and 5.4; baked beans, 3.2 and 1.2; bread, 9.5 and 2.7; and garden vegetables dinner, 9.8 and 5.0. The efficiency of $\mathrm{Fe}$ absorption from the commercial foods with a lower Fe concentration would probably be higher than was observed for the test meals in our study.

There are no published data on Fe bioavailability from the foods examined in this particular study, but some indication can be obtained from studies on similar foods. $\mathrm{Hb}$ incorporation of ${ }^{59} \mathrm{Fe}$ added to white flour was $3.68 \%$ with $10 \%$ added bran and 1.76 with $40 \%$ added bran in adult men (26). The difference in dietary fiber content between wholemeal and white flour would be provided by approximately $3 \%$ bran (27), thus the $\mathrm{Hb}$ incorporation results from the wholemeal bread sandwich given without ascorbic acid to infants (3.1\% of dose) were in close agreement with adult values for white flour with $10 \%$ added bran. The Fe bioavailability from whole-wheat flour processed into Weetabix breakfast cereal, and given with milk, was similar $(3.0 \%)$.

The proportion of baked beans to tomato sauce in the test meal was 2.5:1. Fe utilization from baked beans per se has not been investigated, but $\mathrm{Fe}$ absorption from soybean flour by children ( 5 mo to 2 y of age) has been shown to vary according to the way it is cooked (16). When boiled, $2.8 \%$ was absorbed, but when baked, absorption rose to $9.4 \%$. In rapidly growing infants with low Fe stores, it is likely that almost all of the absorbed $\mathrm{Fe}$ is used for $\mathrm{Hb}$ synthesis, thus absorption data can be validly compared with utilization data. It would appear, therefore, that the bioavailability of $\mathrm{Fe}$ in baked beans with tomato sauce is somewhere between boiled and baked soybean flour.

Ascorbic acid has been recognized as a potent enhancer of $\mathrm{Fe}$ absorption for many years (28). There are two mechanisms by which it promotes $\mathrm{Fe}$ bioavailability: first, it can reduce $\mathrm{Fe}^{3+}$ to $\mathrm{Fe}^{2+}$, which is more soluble and does not form insoluble hydroxides at such a low $\mathrm{pH}$ as $\mathrm{Fe}^{3+}$, and second it forms a stable complex with $\mathrm{Fe}$, thereby preventing ionic $\mathrm{Fe}$ from forming complexes with dietary constituents, such as tannins and phytate, from which the Fe cannot be removed for uptake into the gastrointestinal mucosal cell. The effect is dose-dependent, and with adults, a threshold of $25 \mathrm{mg}$ is indicated, and doses of $50 \mathrm{mg}$ per meal have been suggested as optimal (29). The ascorbic acid:Fe molar ratio is another important consideration. Molar ratios of about 1.5 can result in a 2- to 3-fold increase in $\mathrm{Fe}$ absorption from Fe-fortified cereals (30). The present study showed a 2 -fold increase in $\mathrm{Fc}$ utilization from baked beans, wholemeal bread, and Weetabix. The ascorbic acid:Fe molar ratios were all well in excess of 1.5 , 
ranging from 6.7 for baked beans to 14.7 for the garden vegetables dinner, thus an enhancement of Fe bioavailability would be anticipated. However, no significant increase in Fe bioavailability was found with the garden vegetables dinner. This product is normally fortified with ascorbic acid, and the analyzed concentration was $63 \mathrm{mg} / \mathrm{meal}$. Thus the ascorbic acid:Fe ratio was 8.1, without the additional ascorbic acid from the fruit juice drink, which was high enough to promote $\mathrm{Fe}$ absorption from the meal alone.

In conclusion, the results of this study showed no significant difference in Fe bioavailability to 9-mo-old infants from four different weaning foods, but demonstrated a significant (2-fold) increase when foods low in ascorbic acid were given with a fruit juice drink containing $50 \mathrm{mg}$ of ascorbic acid.

Acknowledgments. The authors thank the research nurses Sheila Sills and Dee Scott for their help, Dr. Jim Cook for ferritin analysis, Peter Wilson for assistance with the computer programs, SmithKline Beecham for the apple juice drinks, Weetabix, and Milupa for Fe-free commercial products, and all the mothers for volunteering their babies.

\section{REFERENCES}

1. Fairweather-Tait SJ 1989 Iron in food and its availability. Acta Paediatr Scand Suppl $361: 12-20$

2. Haschke F, Pietschnig B, Vanura H, Heil M, Steffan I, Hobiger G, Schuster E, Camaya $\mathrm{Z} 1988$ Iron intake and nutritional status of infants fed iron-fortified beikost with meat. Am J Clin Nutr 47:108-112

3. Fairweather-Tait SJ 1992 Iron deficiency in infancy; easy to prevent-or is it? Eur J Clin Nutr 46 (suppl 4):S9-S14

4. Cook JD, Layrisse M, Martinez-Torres C, Walker R, Monsen E, Finch CA 1972 Food iron absorption mcasured by an extrinsic tag. J Clin Invest 51:805-815

5. Sandstrom B, Fairweather-Tait SJ, Hurrell R, Van Dokkum W 1993 Methods for studying mincral and trace clement absorption in humans using stable isotopes. Nutr Res Rev 6:71-95

6. Fairweather-Tait S 1993 Iron. Flair Concerted Action No. 10 Status Papers. Int Vitam Nutr Res 63:296-301

7. Fairweather-Tail SJ, Wright AJA 1990 The effects of sugar-beet fibre and wheat bran on iron and zinc absorption in rats. Br J Nutr 64:547-552

8. Finglas PM, Bailey A, Walker A, Loughridge JM, Wright AJA, Southon S 1993 Vitamin $C$ intake and plasma ascorbic acid concentrations in adolescents. Br J Nutr $69: 563-576$
9. Kuhn IN, Monsen ER, Cook JD, Finch CA 1968 Iron absorption in man. J Lab Clin Med 71:715-721

10. Kastenmayer P, Davidsson L, Galan P, Cherouvrier F, Hercberg S, Hurrell RF 1994 A double stable isotope technique for measuring iron absorption in infants. Br J Nutr 71:411-424

11. Lentner C (Ed) 1984 Gcigy Scientific Tables 3. Ciba-Geigy, Basle, Switzerland

12. Cook JD, Layrisse M, Finch CA 1969 The measurement of iron absorption. Blood 33:421-429

13. Payne RW, Lane PW, Ainsley AE, Bicknell KE, Digby PGN, Harding SA, Leech PK, Simpson HR, Todd AD, Verrier PJ, White RP, Gower JC, Tunniclife-Wilson G, Patterson LJ 1987 GENSTAT 5 Reference Manual. Clarendon Press, Oxford

14. Snedecor GW, Cochran WG 1967 Statistical Methods. Iowa State University Press, Ames, IA

15. Cook JD, Bothwell TH 1984 Availability of iron from infant foods. In: Stekel A (ed) Iron Nutrition in Infancy and Childhood. Nestle, Vevey. Raven Press, New York, pp $119-145$

16. Ashworth A, Milner PF, Waterlow JC, Walker RB 1973 Absorption of iron from maize (Zea mays L.) and soya beans (Glycine hispida Max.) in Jamaican infants. Br J Nutr 29:269-278

17. Schultz J, Smith NJ 1958 A quantitative study of the absorption of food iron in infants and children. Am J Dis Child 95:109-119

18. Rios E, Hunter RE, Cook JD, Smith NJ, Finch CA 1975 The absorption of iron as supplements in infant cereal and infant formulas. Pediatrics 55:686-693

19. Fairweather-Tait SJ, Balmer SE, Scott PH, Minski MJ 1987 Lactoferrin and iron absorption in newborn infants. Pedediatr Res 22:651-654

20. Fomon SJ, Ziegler EE, Rogers RR, Nelson SE, Edwards BB, Guy DG, Erve JC, Janghorbani MJ 1989 Iron absorption from infant foods. Pediatr Res 26:250-254

21. Fomon SJ, Janghorbani M, Ting BTG, Ziegler EE, Rogers RR, Nelson SE, Ostcdgaard LS, Edwards BB 1988 Erythrocyte incorporation of ingested 58-iron by infants. Pediatr Res 24:20-24

22. Davidsson L, Kastenmayer P, Yuen M, Lonnerdal B, Hurrell RF 1994 Influence of lactoferrin on iron absorption from human milk in infants. Pediatr Res 35:117-124

23. Sicgel S 1956 Nonparametric Statistics for the Bchavioural Sciences. McGraw-Hill Kogakusha Ltd, Tokyo, pp 202-213

24. Fairweather-Tait SJ, Wright AJA 1987 The importance of status and previous diet of animals on the estimation of bioavailability of different forms of metallic elements: studies on Fe. Toxicol Environ Chem 13:223-228

25. Hurrell RF, Furniss DE, Burri J, Whittaker P, Lynch SR, Cook JD 1989 Iron fortification of infant cercals: a proposal for the usc of ferrous fumarate or ferrous succinate. Am J Clin Nutr 49:1274-1282

26. Bjorn-Rasmussen E 1974 Iron absorption from wheat bran. Nutr Metab 16:101-110

27. Paul AA, Southgate DAT 1978 McCance \& Widdowson's The Composition of Foods. HMSO, London

28. Moore CV, Dubach R 1951 Observations on the absorption of iron from foods tagged with radioiron. Trans Assoc Am Physicians 64:245-256

29. Hallberg L, Brune M, Rossander L 1986 Effect of ascorbic acid on iron absorption from different types of meals. Hum Nutr Appl Nutr 40A:97-113

30. Derman DP, Bothwell TH, MacPhail AP, Torrance JD, Bezwoda WR, Charlton RW, Mayet F 1980 Importance of ascorbic acid in the absorption of iron from infant foods. Scand J Haematol 25:193-201 